\title{
Estimation of bioaccessibility and potential human health risk of mercury in Chinese patent medicines
}

\author{
Lihong Liu' ${ }^{1}$, Yu Zhang ${ }^{2}$, Zhaojun Yun ${ }^{1}$, Bin He ${ }^{1, *}$, Guibin Jiang ${ }^{1}$ \\ 1. State Key Laboratory of Environmental Chemistry and Ecotoxicology, Research Centre for Eco-Environmental Sciences, Chinese Academy of Sciences, \\ P.O. Box 2871, Beijing 100085, China. E-mail: Ihliu@rcees.ac.cn \\ 2. Wangjing Hospital, China Academy of Chinese Medical Sciences, Beijing 100102, China
}

\section{A R T I C L E I N F O}

Article history:

Received 31 July 2015

Revised 19 October 2015

Accepted 21 October 2015

Available online 23 December 2015

Keywords:

Bioaccessibility

Mercury

Chinese patent medicine

Simulated digestion extraction

\begin{abstract}
A B S T R A C T
Mercury (Hg), mainly in cinnabar species, has been used in medicine for thousands of years in China, and worldwide concern has been raised on its toxicity. In this work, the amount of bioaccessible mercury in 16 Chinese patent medicines (CPMs) was measured by using an in vitro simulated digestion system, consisting of simulated gastric and intestinal fluid, to investigate the bioavailability of mercury in CPMs and evaluate its potential risk to human health. Total mercury and mercury in the gastrointestinal extracts were measured by inductively coupled plasma mass spectrometry (ICP-MS). The levels of total Hg in 16 CPMs ranged from not detected to $11.89 \mathrm{mg} / \mathrm{g}$, with a mean value of $1.13 \mathrm{mg} / \mathrm{g}$, while the extractable $\mathrm{Hg}$ ranged from not detected to $4.37 \mu \mathrm{g} / \mathrm{g}$, with a mean value of $0.42 \mu \mathrm{g} / \mathrm{g}$. Mercury bioaccessibility varied significantly in the investigated CPMs, depending on the ingredient. Compared to the CPMs without cinnabar (2.5\%-30.9\%), the percentage of mercury in the gastrointestinal supernatants for CPMs with cinnabar was quite a bit lower (0.037\%). By comparing with the Food and Agricultural Organization/World Health Organization Joint Expert Committee on Food Additives (FAO/WHO) safety guideline, the average daily intake dose (ADD) of $\mathrm{Hg}$ in the medicines was then calculated to access the risk of mercury to human health from taking CPMs.

(c) 2015 The Research Center for Eco-Environmental Sciences, Chinese Academy of Sciences. Published by Elsevier B.V.
\end{abstract}

\section{Introduction}

Traditional Chinese medicine (TCM) has been widely used in many eastern countries for thousands of years and spread all over the world. The U.S. botanical market is a booming industry, amounting to about 1.5 billion dollars in 1995 and probably growing at about 15\% a year (Marwick, 1995). Chinese patent medicine (CPM) is one type of TCM, which is composed of different ingredients, such as prescriptive botanicals, animal tissues or minerals. CPMs may come in different forms such as pills, powders, syrups, liquids, tablets, granules and capsules. As alternative or complementary medicine, even though TCMs are perceived to be natural and thus harmless by many consumers, problems might arise because of contamination, the lack of adequate regulations and the pharmacological complexity of herbal products (Ernst, 1998, 2002). Along with the popularity of TCM, more and more concerns about the quality and safety of the medicines have been raised nowadays (Ernst, 1998, 2002; Kim et al., 2013). For instance, heavy metals, such as mercury, lead, arsenic, and cadmium, have been previously reported to be present in TCMs (Ting et al., 2013). In the 251 CPMs obtained from California herbal retail stores, 35 contained an average of $1046 \mu \mathrm{g} / \mathrm{g}$ mercury, 36 contained an average of $14.6 \mu \mathrm{g} / \mathrm{g}$ arsenic, and 24 contained at least $10 \mu \mathrm{g} / \mathrm{g}$ lead (Ko, 1998). The

\footnotetext{
* Corresponding author. E-mail: bhe@rcees.ac.cn (Bin He).
} 
concentrations of toxic heavy metals in 42 of 2080 TCMs were found to exceed Singapore's legal limits, including 28 for mercury, 6 for arsenic, and 8 for lead (Ernst, 2002; Koh and Woo, 2000). Such issues were also reported in Europe (Melchart et al., 1999; Zhang et al., 2012) and Japan (Itoh et al., 1995).

Mercury is considered one of the most toxic elements in the environment and it can cause many diseases and side effects in human beings, especially to the nervous system. Therefore, CPMs containing Hg are expected to pose significant health risks. Cases of mercury poisonings from taking CPMs have been reported (Ernst and Coon, 2001). Mercury in CPMs can originate from the accumulation of $\mathrm{Hg}$ in the raw materials and/or inadvertent contamination during the production process (Zhang et al., 2012). Besides contamination, deliberate addition for specific curative purposes is another reason for the high concentration of $\mathrm{Hg}$ in CPMs. Cinnabar, a naturally occurring mineral containing more than $96 \%$ mercury sulfide (HgS), has been widely used in CPMs for more than 2000 years due to its sedative and hypnotic function (Lu et al., 2011). There are 63 prescriptions containing cinnabar among the 1060 Chinese medicinal prescriptions recorded in the latest Chinese pharmacopeia (Pharmacopeial Committee of China, 2010).

Generally, it is assumed that $100 \%$ of the $\mathrm{Hg}$ is absorbed by the human body and therefore, the total $\mathrm{Hg}$ level is usually taken as the most important criteria for evaluation of the toxicity and health impact of taking medicines. Human health risk associated with exposure to mercury by taking CPMs has been evaluated in several previous studies by estimating the total amount of $\mathrm{Hg}$ ingested (Chui et al., 2013; Liu et al., 2012). However, only the bioavailable portion of $\mathrm{Hg}$ can be absorbed by humans and transported into the blood stream, freely cross cellular membranes and redistribute around the body. Therefore, the potential toxicity could be overestimated in these studies without considering the bioavailability of $\mathrm{Hg}$. The toxicity of $\mathrm{Hg}$ in CPMs depends not only on the total concentration, but also on its bioavailability, which can be absorbed and finally reach systemic circulation. Therefore, determining the amount of bioavailable $\mathrm{Hg}$ in the CPMs is necessary for appropriately assessing the health risk of consuming CPMs.

Due to the disadvantages of in vivo methods for bioavailability determination, e.g., being time consuming, expensive, and complicated, an in vitro method for determining bioaccessibility (fraction dissolved in the digestive system and potentially available for absorption) has been commonly used to estimate the bioavailability of metals in real samples (Koch et al., 2007). The in vitro extraction can be strongly affected by various conditions, such as temperature, $\mathrm{pH}$, agitation and extract composition, which should be similar to those in the human body during digestion. Simulated body fluid (SBF) tests have been used to study the bioaccessibility of several metals in food (Juhasz et al., 2006; Moreda-Pineiro et al., 2011), soil (Kientz et al., 2003), and sediment (Semple et al., 2004), in which the bioaccessible fraction was extracted by using simulated gastric fluid (SGF) or SGF and simulated intestinal fluid (SIF) together. Cabanero et al. (2004) have used the SBF test to study the $\mathrm{Hg}$ bioaccessibility in fishes. Their results showed that the proportion of bioaccessible $\mathrm{Hg}$ in fishes ranged from $9 \%-17 \%$, depending on the species. However, to the best of our knowledge, none of the previous studies investigated the bioaccessibility of $\mathrm{Hg}$ in CPMs.
In this work, we attempted to determine the total and bioaccessible amount of $\mathrm{Hg}$ in 16 commonly used CPMs. In order to study the bioaccessibility of $\mathrm{Hg}$ in the CPMs, an in vitro SBF test, including SGF and SIF phase extractions, were performed to simulate the gastric and intestinal digestion process in the human body. The total and SGF/SIF extractable $\mathrm{Hg}$ was then determined by inductively coupled plasma mass spectrometry (ICP-MS). Finally, the average daily intake dose (ADD) was calculated to assess the potential health risk of taking these CPMs.

\section{Materials and methods}

\subsection{Chemicals and reagents}

Mercury stock standard solution (1000 mg/L as $\mathrm{Hg}$ ) was prepared by dissolving mercury chloride ( $\geq 99.5 \%$, Beijing Chemical Reagents Company, Beijing, China) in deionized water and then stored in the dark at $4^{\circ} \mathrm{C}$. Au solution $(1000 \mathrm{mg} / \mathrm{L} \mathrm{Au})$ was purchased from Inorganic Ventures (Christiansburg, USA). Hg working solutions were prepared by diluting a certain amount of the stock standard solution in 3\% $\mathrm{HNO}_{3}$ (65\%, Merck, Darmstadt, Germany) containing $100 \mathrm{ng} / \mathrm{mL}$ $\mathrm{Au}$. All other chemicals used were analytical or higher grade. De-ionized water (18.2 $\mathrm{M} \Omega \mathrm{cm}$ ) was made by a Milli-Q Advanced A10 ultrapure water system (Millipore, Bedford, USA).

Both SGF and SIF were prepared according to the procedure described in the U.S. Pharmacopeia (United States Pharmacopeial Convention, 2004). The SGF was prepared by dissolving $3.2 \mathrm{~g}$ of pepsin (from porcine gastric mucosa, 920 units/mg protein, Sigma-Aldrich Co. LLC, USA) and $2 \mathrm{~g}$ of $\mathrm{NaCl}$ in $7.0 \mathrm{~mL}$ of concentrated $\mathrm{HCl}$. Then the mixture was diluted to $1 \mathrm{~L}$ with de-ionized water, and the $\mathrm{pH}$ of the final solution was about 1.2. The SIF was prepared by dissolving $6.8 \mathrm{~g} \mathrm{KH}_{2} \mathrm{PO}_{4}$ in $250 \mathrm{~mL}$ de-ionized water, adding in sequence $77 \mathrm{~mL}$ of $0.2 \mathrm{~mol} / \mathrm{L} \mathrm{NaOH}$, $500 \mathrm{~mL}$ of de-ionized water, and $10.0 \mathrm{~g}$ of pancreatin (from porcine pancreas, $8 \times$ USP specifications, Sigma-Aldrich Co. LLC, USA). Then the mixture was diluted to $1 \mathrm{~L}$ with de-ionized water, and the $\mathrm{pH}$ of the final solution was about 6.8.

\subsection{ICP-MS system}

An Agilent 7500ce ICP-MS (Agilent Technologies, USA) was used for the $\mathrm{Hg}$ quantification. A Babington nebulizer was fitted on the double-pass spray chamber. The ICP-MS instrument performance conditions, including nebulizer gas flow rate, carrier gas flow rate, makeup gas flow rate, and lens voltage, were tuned and optimized daily. The optimized parameters are shown in Table 1. In order to eliminate memory interference effects of $\mathrm{Hg}$ in the ICP-MS system, an aliquot of Au stock solution was added to all blanks, calibration standards and samples to form a final concentration of $100 \mathrm{ng} / \mathrm{mL}$ Au in all the solutions (U.S. Environmental Protection Agency, 1994). The concentrations of $\mathrm{Hg}$ in the microwave-digested samples, gastric phase and intestinal phase extracted samples were analyzed by using the external calibration method. Bismuth (Bi) was used as an internal standard to correct for changes caused by the variation of matrix components of different samples and the instrument drift during measurement. 
Table 1-The instrumental parameters of inductively coupled plasma mass spectrometry (ICP-MS).

Parameters

\begin{tabular}{ll}
\hline Spray chamber & Double-pass spray chamber \\
Nebulizer & Babington nebulizer \\
Interface & Ni cones \\
Chamber temperature & $2{ }^{\circ} \mathrm{C}$ \\
RF power & $1500 \mathrm{~W}$ \\
Carrier gas & $0.85 \mathrm{~L} / \mathrm{min}$ \\
Makeup gas & $0.15 \mathrm{~L} / \mathrm{min}$ \\
Acquired mode & $\mathrm{Spectrum}$ \\
Isotopes monitored & ${ }^{202} \mathrm{Hg},{ }^{209} \mathrm{Bi}$ (internal standard) \\
\hline
\end{tabular}

\subsection{Sample collection and pretreatment}

Sixteen commonly used CPMs were purchased from a local pharmacy (Beijing, China). The names and ingredients of the medicines are listed in Table 2. Among the 16 samples, there were 2 cinnabar-containing CPMs, including 1 capsule medicine (FFLHJN) and 1 pill medicine (TRASW), and 14 CPMs without cinnabar, including 2 granule medicines (BLGKL and GMQRKL), 4 tablet medicines (FFDSP, NHJDP, SHP and YQJDP), and 8 pill medicines (BZYQW, HLSQW, LQBDW, LWDHW,
NHJDW, NHQHW, QJDHW and ZBDHW). Honey is contained in all the honeyed pill and water-honeyed pill medicines as excipient, while sucrose and dextrin are present in the two granule medicines.

All the samples were cut into small pieces and then freeze-dried at $-45^{\circ} \mathrm{C}$ for more than $48 \mathrm{hr}$ to achieve constant weight. The freeze-dried samples were ground in an agate grinder to obtain homogeneous fine particles and preserved at $-20^{\circ} \mathrm{C}$ ahead of further treatments.

Before determination, the samples were digested by a Mars5 HP500 microwave accelerated reaction system (CEM Corporation, USA). Firstly, 0.5 g samples were weighed exactly into PTFE digestion vessels, then $3 \mathrm{~mL}$ concentrated $\mathrm{HNO}_{3}$ and $3 \mathrm{~mL} \mathrm{30 \% (V/V)} \mathrm{H}_{2} \mathrm{O}_{2}$ were added into each vessel. The vessels were sealed and placed into the microwave system. The temperature was first raised to $120^{\circ} \mathrm{C}$ and maintained for $5 \mathrm{~min}$, then increased to $160^{\circ} \mathrm{C}$ in $6 \mathrm{~min}$, held for $8 \mathrm{~min}$ and then increased to $180^{\circ} \mathrm{C}$. After holding at $180^{\circ} \mathrm{C}$ for $30 \mathrm{~min}$, the vessels were cooled down to room temperature. The digestion solutions were entirely transferred to PET bottles and diluted with de-ionized water for total Hg analysis by ICP-MS.

The in vitro bioaccessible $\mathrm{Hg}$ was extracted by using simulated body fluids, including SGF and SIF phases. Unlike

Table 2 - Ingredients of the selected Chinese patent medicines.

\begin{tabular}{|c|c|c|}
\hline Name & Ingredients & Description \\
\hline $\begin{array}{l}\text { Ban Lan Gen Ke Li } \\
\text { (BLGKL) }\end{array}$ & Isatis tinctoria L. & Granule \\
\hline $\begin{array}{l}\text { Gan Mao Qing Re Ke Li } \\
\text { (GMQRKL) }\end{array}$ & $\begin{array}{l}\text { Nepeta cataria, Mentha haplocalyx, Saposhnikovia divaricata, Radix Bupleuri, Perilla frutescens, } \\
\text { Pueraria lobata, Platycodon grandiflorus, Semen Armeniacae Amarum, Angelica dahurica, Herba } \\
\text { Corydalis Bungeanae, Rhizoma Phragmitis }\end{array}$ & Granule \\
\hline $\begin{array}{l}\text { Fu Fang Dan Shen Pian } \\
\text { (FFDSP) }\end{array}$ & Salvia miltiorrhiza Bunge, Panax pseudoginseng, Borneolum. & Film coated tablet \\
\hline $\begin{array}{l}\text { Niu Huang Jie Du Pian } \\
\text { (NHJDP) }\end{array}$ & $\begin{array}{l}\text { Ligularia duciformis, Scutellaria baicalensis, Gypsum Fibrosuum, Realgar, Platycodon grandiflorus, } \\
\text { Glycyrrhiza uralensis, Bovis Calculus Artifactus, Borneolum }\end{array}$ & Film coated tablet \\
\hline San Huang Pian (SHP) & Ligularia duciformis, Berberine Hydrochloride, Scutellaria baicalensis & Sugar coated tablet \\
\hline $\begin{array}{l}\text { Yin Qiao Jie Du Pian } \\
\text { (YOJDP) }\end{array}$ & $\begin{array}{l}\text { Lonicera japonica, Forsythia suspensa, Mentha haplocalyx, Nepeta cataria, Semen Sojae Preparatum, } \\
\text { Arctium lappa, Platycodon grandiflorus, Lophatherum gracile, Glycyrrhiza uralensis }\end{array}$ & Tablet \\
\hline $\begin{array}{l}\text { Bu Zhong Yi Qi Wan } \\
\text { (BZYQW) }\end{array}$ & $\begin{array}{l}\text { Astragalus membranaceus, Codonopsis pilosula, Glycyrrhiza uralensis, Atractylodes } \\
\text { macrocephala, Angelica sinensis, Cimicifuga foetida, Radix Bupleuri, Citrus sinensis }\end{array}$ & Watered pill \\
\hline $\begin{array}{l}\text { Huang Lian Shang Qing Wan } \\
\text { (HLSQW) }\end{array}$ & $\begin{array}{l}\text { Coptis chinensis, Gardenia jasminoides, Forsythia suspensa, Fructus Vitics Simplicifoliae, } \\
\text { Saposhnikovia divaricata, Nepeta cataria, Angelica dahurica, Scutellaria baicalensis, Dendranthema } \\
\text { morifolium, Mentha haplocalyx, Rheum officinale, Phellodendron amurense, Platycodon grandiflorus, } \\
\text { Ligusticum chuanxiong, Gypsum Fibrosuum, Inula japonica, Glycyrrhiza uralensis }\end{array}$ & Honeyed pill \\
\hline $\begin{array}{l}\text { Lian Qiao Bai Du Wan } \\
\text { (LQBDW) }\end{array}$ & $\begin{array}{l}\text { Forsythia suspensa, Lonicera japonica, Herba Corydalis Bungeanae, Radix Trichosanthis, } \\
\text { Scutellaria baicalensis, Coptis chinensis, Phellodendron amurense Rupr., Ligularia duciformis, } \\
\text { Sophora flavescens, Nepeta cataria, Saposhnikovia divaricata, Angelica dahurica, Notopterygium } \\
\text { incisum, Ephedra sinica, Mentha haplocalyx, Radix Bupleuri, Angelica sinensis, Radix Paeoniae } \\
\text { Rubra, Glycyrrhiza uralensis }\end{array}$ & Watered pill \\
\hline $\begin{array}{l}\text { Liu Wei Di Huang Wan } \\
\text { (LWDHW) }\end{array}$ & $\begin{array}{l}\text { Rehmannia glutinosa, Cornus officinalis, Cortex Moutan, Rhizoma Dioscoreae, Poria cocos, Alisma } \\
\text { plantago-aquatica }\end{array}$ & Water-honeyed pill \\
\hline $\begin{array}{l}\text { Niu Huang Jie Du Wan } \\
\text { (NHJDW) }\end{array}$ & $\begin{array}{l}\text { Ligularia duciformis, Scutellaria baicalensis, Gypsum Fibrosuum, Realgar, Platycodon } \\
\text { grandiflorus, Glycyrrhiza uralensis, Bovis Calculus Artifactus, Borneolum }\end{array}$ & Honeyed pill \\
\hline $\begin{array}{l}\text { Niu Huang Qing Huo Wan } \\
\text { (NHQHW) }\end{array}$ & $\begin{array}{l}\text { Ligularia duciformis, Scutellaria baicalensis, Rhizoma Dioscoreae, Realgar, Mentholum, } \\
\text { Platycodon grandiflorus, Syringa Linn., Bovis Calculus Artifactus, Borneolum }\end{array}$ & Honeyed pill \\
\hline $\begin{array}{l}\text { Qi Ju Di Huang Wan } \\
\text { (QJDHW) }\end{array}$ & $\begin{array}{l}\text { Fructus Lycii, Dendranthema morifolium, Rehmannia glutinosa, Cornus officinalis, Cortex } \\
\text { Moutan, Rhizoma Dioscoreae, Poria cocos, Alisma plantago-aquatica }\end{array}$ & Water-honeyed pill \\
\hline $\begin{array}{l}\text { Zhi Bai Di Huang Wan } \\
\text { (ZBDHW) }\end{array}$ & $\begin{array}{l}\text { Anemarrhena asphodeloides Bunge, Phellodendron amurense Rupr., Rehmannia glutinosa, } \\
\text { Cornus officinalis, Cortex Moutan, Rhizoma Dioscoreae, Poria cocos, Alisma plantago-aquatica }\end{array}$ & Water-honeyed pill \\
\hline $\begin{array}{l}\text { Fu Fang Lu Hui Jiao Nang } \\
\text { (FFLHJN) }\end{array}$ & Aloe vera, Indigo Naturalis, Cinnabaris, Succinum & Capsule \\
\hline $\begin{array}{l}\text { Tong Ren An Shen Wan } \\
\text { (TRASW) }\end{array}$ & $\begin{array}{l}\text { Coptis chinensis, Glycyrrhiza uralensis, Rehmannia glutinosa, Angelica sinensis, Astragalus } \\
\text { membranaceus, Semen Ziziphi Spinosae, Dens Draconis, Poria cocos, Semen Platycladi, Cinnabaris }\end{array}$ & Honeyed pill \\
\hline
\end{tabular}




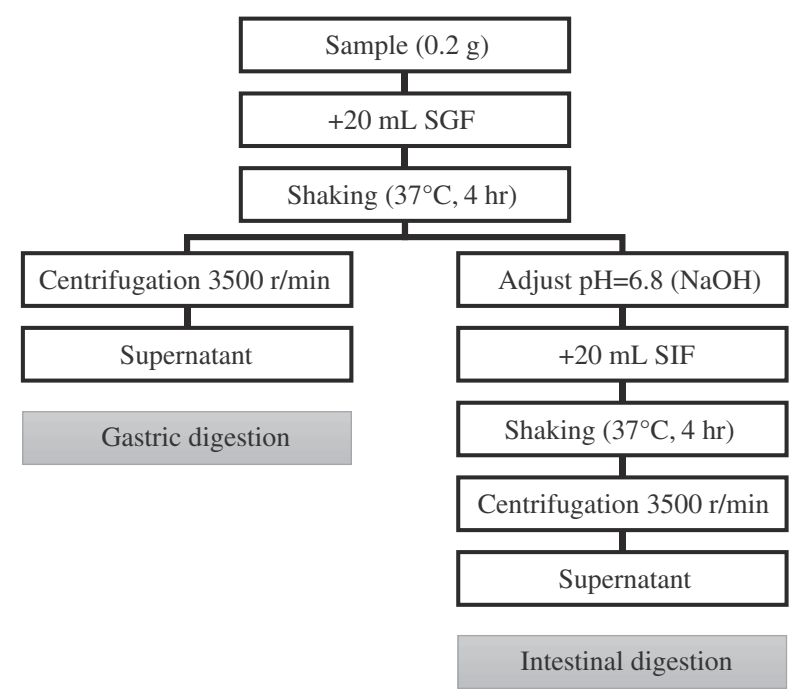

Fig. 1 - Flow chart of the simulated body fluid (SBF) extraction protocol.

other studies (Dufailly et al., 2008), salivary digestion was not included in our SBF extraction process because all the CPMs were swallowed without chewing. The SBF test conditions were set up to be as close to the in vivo situation as possible to simulate the gastric and intestinal digestion process. The solid:liquid ratio was set to $1: 100$ and the two-stage extraction process was similar to that used by others (Cabanero et al., 2004; Koch et al., 2011) with slight modification (Fig. 1). For SGF extraction, $0.2 \mathrm{~g}$ of pulverized CPM sample was placed in a $45 \mathrm{~mL}$ glass vessel with $20 \mathrm{~mL}$ of SGF and vortex mixed for $1 \mathrm{~min}$. The mixtures were shaken at $37^{\circ} \mathrm{C}$ and $150 \mathrm{r} / \mathrm{min}$ for $4 \mathrm{hr}$ by a temperature-controlled shaker (DDHZ-300 oscillator, Taicang City Experimental Equipment Factory, Jiangsu, China). The mixture was then centrifuged at $3500 \mathrm{r} / \mathrm{min}$ for $10 \mathrm{~min}$, and then $15 \mathrm{~mL}$ of the supernatant was filtered through a $0.45 \mu \mathrm{m}$ filter. For SIF extraction, the $\mathrm{pH}$ of the residual mixture was adjusted to 6.8 with $1 \mathrm{~mol} / \mathrm{L} \mathrm{NaOH}$ solution. Twenty milliliters of the SIF was added into the vessel and the same extraction procedure as used for the SGF was adopted. Finally, all the filtrates, representing the bioaccessible fraction, were analyzed for Hg by ICP-MS. The bioaccessibility of $\mathrm{Hg}$ in the CPMs could be calculated following Eq. (1):

$\mathrm{Hg}$ Bioaccessibility $=\frac{\mathrm{Hg} \text { amount in bioaccessible fraction }}{\text { Total Hg in CPM }} \times 100 \%$.

\subsection{Risk assessment}

The adult human weight was assumed to be approximately $60 \mathrm{~kg}$ in this study. The average daily intake dose (ADD, $\mu \mathrm{g} / \mathrm{kg}$ body weight (bw)/day) of bioaccessible Hg for ingesting CPMs can be calculated according to the following equation:

$\mathrm{ADDHg}=\frac{\mathrm{B}_{\mathrm{Hg}} \times \mathrm{C}_{\mathrm{Hg}} \times \mathrm{MRD} \times \mathrm{MRF}}{60}$

where, $B_{\mathrm{Hg}}$ is the bioaccessibility of $\mathrm{Hg}$ in CPMs according the SBF test, $\mathrm{C}_{\mathrm{Hg}}(\mu \mathrm{g} / \mathrm{g})$ is the concentrations of $\mathrm{Hg}$ in the CPMs, $\operatorname{MRD}(\mathrm{g})$ is the maximum recommended doses of the CPMs, and MRF (range from 1 to 3, for instance 2/day represents that the medicine should be taken 2 times a day) is the maximum recommended frequency of the CPMs.

\subsection{Quality assurance and quality control}

For microwave digestion, 16 CPMs were digested with 3 blanks, 2 certified reference materials, TORT-2 (Lobster hepatopancreas reference material, National Research Council Canada, Ontario, Canada) and DORM-3 (fish protein certified reference material, National Research Council Canada, Ontario, Canada) in the same batch, in which SHP, LWDHW, FFLHJN and each certificated reference material had 3 duplicates. Hg in all blanks was less than the detection limit. The Hg concentration in the reference materials of TORT-2 and DORM-3 were $322.0 \pm 5.6 \mathrm{ng} / \mathrm{g}$ and $345.1 \pm 19.8 \mathrm{ng} / \mathrm{g}$, respectively, which were in good agreement with the certified values $(270 \pm 60 \mathrm{ng} / \mathrm{g}$ for TORT-2 and $382 \pm$ $60 \mathrm{ng} / \mathrm{g}$ for DORM-3). RSD of less than 9.1\% was obtained for all the duplicates. Hg in the two blanks of SBF extraction, which was obtained by following the SGF and SIF extraction procedures without adding the CPMs, was less than the detection limit.

The ICP-MS system was rinsed with $3 \% \mathrm{HNO}_{3}$ containing $100 \mathrm{ng} / \mathrm{g}$ Au for at least $2 \mathrm{~min}$ until the $\mathrm{Hg}$ signal was reduced to the background level after each standard solution or sample analysis cycle. The detection limit $(3 \sigma)$ for $\mathrm{Hg}$ of the adopted method was $0.02 \mathrm{ng} / \mathrm{mL}$. Each sample was analyzed in triplicate and the relative standard deviation (RSD) was determined to be less than $3 \%$.

\section{Results and discussion}

\subsection{Total $\mathrm{Hg}$ concentrations in the CPMs}

Total $\mathrm{Hg}$ concentrations in the $16 \mathrm{CPMs}$, including 2 cinnabar-containing CPMs and 14 CPMs without cinnabar, were analyzed by ICP-MS in the experiment, and the results are shown in Fig. 2. The total amount of $\mathrm{Hg}$ varied widely, ranging from not detected to $11.89 \mathrm{mg} / \mathrm{g}$, depending on the CPM ingredients, especially cinnabar. It was remarkable that only the two granule medicines (BLGKL and GMQRKL) were 


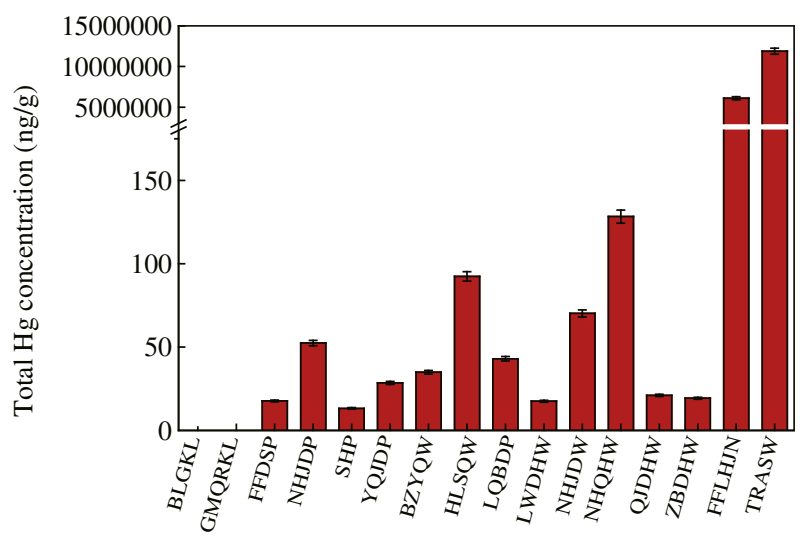

Fig. 2 - Total mercury concentration in the 16 Chinese patent medicines (CPMs).

mercury-free and all the other 14 medicines had a reliably measurable amount of $\mathrm{Hg}$. The two cinnabar-containing CPMs (FFLHJN and TRASW) had the highest Hg concentrations (6.11 mg/g and $11.89 \mathrm{mg} / \mathrm{g}$, respectively), which were four to six orders of magnitude higher than the other 14 medicines (in the range of $0-128.3 \mathrm{ng} / \mathrm{g}$ ). According to the Chinese pharmacopeia, the total amount of $\mathrm{Hg}$ in medicines should be less than $200 \mathrm{ng} / \mathrm{g}$ and the daily intake of cinnabar should be less than $0.5 \mathrm{~g}$ for an adult human (Pharmacopeial Committee of China, 2010). Of the 14 CPMs without cinnabar, all the $\mathrm{Hg}$ concentrations did not exceed the standard limit $(200 \mathrm{ng} / \mathrm{g})$. With respect to the two cinnabar-containing medicines, even though the amounts of $\mathrm{Hg}$ were really high, the calculated daily intakes of cinnabar according to the recommended intake dose were $0.012 \mathrm{~g} /$ day for FFLHJN and $0.265 \mathrm{~g} /$ day for TRASW, respectively, all below the standard limit of $0.5 \mathrm{~g} /$ day. Therefore, all the selected CPMs satisfied the Chinese pharmacopeia's requirements and could be used for therapy with strictly prescribed medication. Moreover, it should be noted that the two cinnabar-containing medicines were not suggested to be taken in excessive dosages or for long periods, and they should be used with extra caution by pregnant women and those with functional disorders of the liver and kidney because of the high concentrations of $\mathrm{Hg}$.

Each CPM was constituted of several natural ingredients, including minerals or tissues of herbal plants and animals and some excipients, such as honey, sucrose or dextrin (Table 2). It was obvious that the high concentrations of $\mathrm{Hg}$ in the FFLHJN and TRASW samples were mainly caused by cinnabar, which was added deliberately for its sedative and hypnotic function. For the other $14 \mathrm{CPMs}$, it is very difficult to distinguish the source of $\mathrm{Hg}$ in the CPMs due to their complex composition and complicated preparation processes. As a ubiquitous pollutant in the environment, $\mathrm{Hg}$ in those CPMs might come from any of the ingredients or be introduced during the preparation process (Ting et al., 2013).

\subsection{Bioaccessibility of $\mathrm{Hg}$ in CPMs}

In general, the toxicity and risk of $\mathrm{Hg}$ in the CPMs is expected to be overestimated when only the total $\mathrm{Hg}$ content is considered. To address this issue, the bioaccessibility of $\mathrm{Hg}$ in the CPMs was investigated in this study. Fourteen CPMs, except for the mercury-free medicines of BLGKL and GMQRKL, were processed by using the proposed SBF test protocol. After sequential extraction by SGF and SIF, the bioaccessible $\mathrm{Hg}$ concentrations of the CPMs were determined by ICP-MS. The bioaccessibility of $\mathrm{Hg}$ was then calculated for each phase by following Eq. (1), and the total Hg bioaccessibility of each CPM was the sum of the $\mathrm{Hg}$ bioaccessibility in the gastric and intestinal phases.

As shown in Fig. 3, the total bioaccessible Hg concentration ranged from 1.53 to $7.41 \mathrm{ng} / \mathrm{g}$ in the $12 \mathrm{CPMs}$ without cinnabar. For the 2 cinnabar-containing medicines, the bioaccessible $\mathrm{Hg}$ concentration was $2.25 \mu \mathrm{g} / \mathrm{g}$ (FFLHJN) and $4.37 \mu \mathrm{g} / \mathrm{g}$ (TRASW). The percentage of bioaccessible $\mathrm{Hg}$ in the $14 \mathrm{CPMs}$ ranged from $0.024 \%$ to $26.7 \%$ in the gastric phase and 0 to $10.2 \%$ in the intestinal phase (Fig. 4). The Hg bioaccessibility of CPMs in the gastric phase was significantly higher than in the intestinal phase. Especially for the SHP and NHJDW samples, Hg was not detected in the intestinal phase. This could be attributed to 1) the properties of the measured samples themselves, and 2) the vastly different $\mathrm{pH}$ (gastric $\mathrm{pH} 1.6$ and intestinal $\mathrm{pH}$ 6.8) and compositions of the gastric and intestinal phases. Mercury solubility in the acidic digestive fluid is assumed to be much higher than that in the neutral fluid. The results were in good agreement with the results for traditional Indian medicines (Jayawardene et al., 2010) and soils (Zagury et al., 2009). These results indicate that the soluble $\mathrm{Hg}$ in most CPMs was mainly dissolved by the gastric fluid, while a small portion of $\mathrm{Hg}$ was digested by the intestinal fluid and then absorbed by humans.

The total Hg bioaccessibility of CPMs, the sum of bioaccessibility of the gastric and intestinal phases, varied widely among individual samples, ranging from $0.037 \%$ to $30.9 \%$. The bioaccessibility of $\mathrm{Hg}$ was in the range of $2.5 \%$ to $30.9 \%$, with an average value of $15.4 \%$ for the CPMs without cinnabar, while it was only $0.037 \%$ for both of the cinnabar-containing medicines. The low bioaccessibility of $\mathrm{Hg}$ in the cinnabar-containing CPMs may be due to the poor solubility of cinnabar at both acid and neutral $\mathrm{pH}$ in the extractants. Previous in vivo and in vitro studies also found that the bioavailability or absorption of cinnabar was quite low (less than $0.2 \%$ ) compared to that of $\mathrm{HgCl}_{2}$ and methyl mercury (Liu et al., 2008). The same bioaccessibility of $\mathrm{Hg}$ in the two cinnabar-containing CPMs further indicated that $\mathrm{Hg}$ in FFLHJN and TRASW were mostly from the addition of cinnabar. 


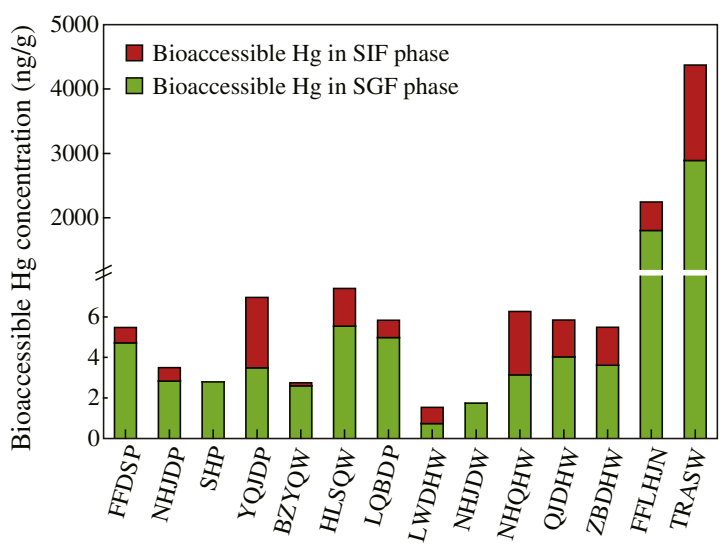

Fig. 3 - The bioaccessible Hg concentration of CPMs in simulated gastric fluid (SGF) and simulated intestinal fluid (SIF) phases.

\subsection{Potential health risk characterization of intake of CPMs}

The ADD of Hg by taking CPMs was calculated based on the SBF test results and the recommended dosage according to Eq. (2). In accordance with conservative principles, the maximum dose of each CPM described by the recommendation was selected in the calculation. Jayawardene et al. (2010) estimated the daily amounts of bioaccessible metal by using the metal concentration in the intestinal phase rather than the gastric-intestinal phase. However, in this study, Hg concentration in the gastric phase was significantly higher than that in the intestinal phase. To avoid underestimating the risk of $\mathrm{Hg}$ in CPMs, ADD of bioaccessible $\mathrm{Hg}$ was calculated by using the total bioaccessibility of $\mathrm{Hg}$.

As shown in Fig. 5, the ADD of bioaccessible $\mathrm{Hg}$ in the CPMs ranged from 0 to $1.63 \mu \mathrm{g} / \mathrm{kg}$ bw/day. Of the $16 \mathrm{CPMs}$ investigated in this study, the ADD of bioaccessible Hg were not detected in 2 samples (BLGKL and GMQRKL), in the range of 0.093 to $1.4 \mathrm{ng} / \mathrm{kg}$ bw/day in the $12 \mathrm{CPMs}$ without cinnabar, and $0.075 \mu \mathrm{g} / \mathrm{kg}$ bw/day and $1.63 \mu \mathrm{g} / \mathrm{kg}$ bw/day in the cinnabarcontaining medicines FFLHJN and TRASW, respectively. The safety guideline of FAO/WHO (Joint FAO/WHO Expert Committee on Food Additives, 2011) for provisional tolerable weekly intake (PTWI) of $\mathrm{Hg}$ was $4 \mu \mathrm{g} / \mathrm{kg}$ bw/week, corresponding to $0.57 \mu \mathrm{g} / \mathrm{kg}$ bw/day. Compared to the PTWI of $0.57 \mu \mathrm{g} / \mathrm{kg}$ bw/day, the ADD of $\mathrm{Hg}$ in the CPMs without cinnabar was 2 to 4 orders of magnitude lower. It is noted that although the total Hg concentration in FFLHJN was high, the ADD of bioaccessible $\mathrm{Hg}(0.075 \mu \mathrm{g} / \mathrm{kg}$ bw/day) was still within the safe level, due to its poor bioaccessibility and low recommended dose. TRASW was estimated to have a Hg ADD exceeding the safety guideline, indicating its potential hazardous risk to humans.

\section{Conclusions}

In this work, $\mathrm{Hg}$ concentrations in the CPMs were investigated and found at different levels. Although the total Hg amounts in cinnabar-containing CPMs are high, all of them could satisfy the Chinese pharmacopeia's requirements for the recommended dose. The bioaccessibility of $\mathrm{Hg}$ in different CPMs varied substantially and was quite a bit lower in cinnabar-containing medicines $(0.037 \%)$ than in medicines without cinnabar $(2.5 \%-31 \%)$. Compared to the safety guidelines for acceptable $\mathrm{Hg}$ intake by FAO/WHO, only TRASW exceeded the safety range, which should be paid attention to based on its health risk by $\mathrm{Hg}$ ingestion. Results suggested that the bioaccessible $\mathrm{Hg}$ should be considered a more scientific and rational measure for evaluating the health risk of taking CPMs than the total concentration, especially for cinnabar-containing CPMs.

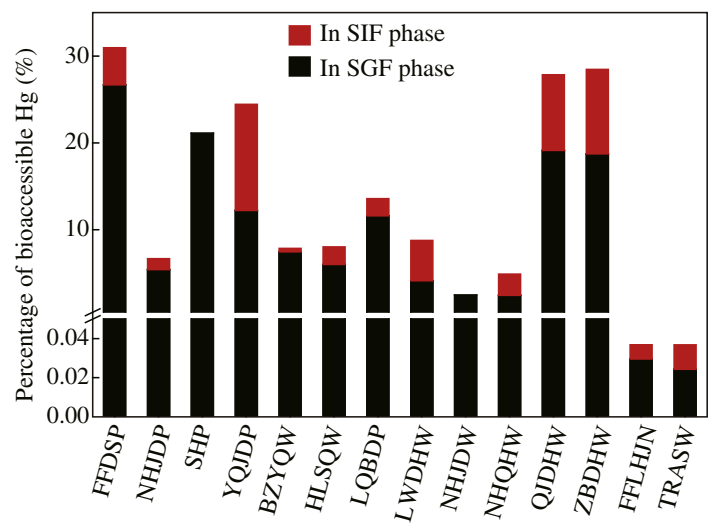

Fig. 4 - Percentage of bioaccessible Hg in CPMs. 


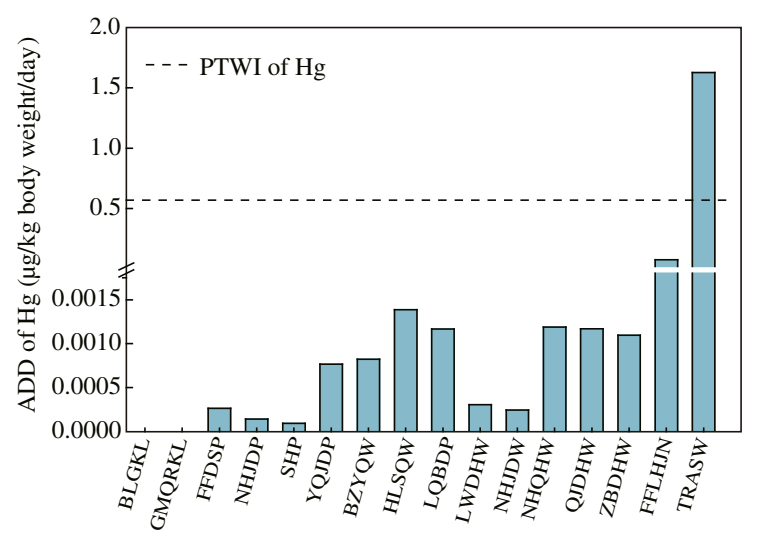

Fig. 5 - Average daily intake dose (ADD) of bioaccessible $\mathrm{Hg}$ in the 16 CPMs.

\section{Acknowledgments}

This work was supported by the National Basic Research Program (973) of China (No. 2013CB430004) and the National Natural Science Foundation of China (Nos. 21120102040, 21075130).

\section{R E F E R E N C E S}

Cabanero, A.I., Madrid, Y., Camara, C., 2004. Selenium and mercury bioaccessibility in fish samples: an in vitro digestion method. Anal. Chim. Acta 526 (1), 51-61.

Chui, S.H., Wong, Y.H., Chio, H.I., Fong, M.Y., Chiu, Y.M., Szeto, Y.T., et al., 2013. Study of heavy metal poisoning in frequent users of Chinese medicines in Hong Kong and Macau. Phytother. Res. 27 (6), 859-863.

Dufailly, V., Guerin, T., Noel, L., Fremy, J.M., Beauchemin, D., 2008. A simple method for the speciation analysis of bio-accessible arsenic in seafood using on-line continuous leaching and ion exchange chromatography coupled to inductively coupled plasma mass spectrometry. J. Anal. Atom. Spectrom. 23 (9), 1263-1268.

Ernst, E., 1998. Harmless herbs? A review of the recent literature. Am. J. Med. 104 (2), 170-178.

Ernst, E., 2002. Toxic heavy metals and undeclared drugs in Asian herbal medicines. Trends Pharmacol. Sci. 23 (3), 136-139.

Ernst, E., Coon, J.T., 2001. Heavy metals in traditional Chinese medicines: a systematic review. Clin. Pharmacol. Ther. 70 (6), 497-504.

Itoh, S., Marutani, K., Nishijima, T., Matsuo, S., Itabashi, M., 1995. Liver injuries induced by herbal medicine, SYO-SAIKO-TO (XIAO-CHAI-HU-TANG). Dig. Dis. Sci. 40 (8), 1845-1848.

Jayawardene, I., Saper, R., Lupoli, N., Sehgal, A., Wright, R.O., Amarasiriwardena, C., 2010. Determination of in vitro bioaccessibility of $\mathrm{Pb}, \mathrm{As}, \mathrm{Cd}$ and $\mathrm{Hg}$ in selected traditional Indian medicines. J. Anal. Atom. Spectrom. 25 (8), 1275-1282.

Joint FAO/WHO Expert Committee on Food Additives (JECFA), 2011. Safety evaluation of certain contaminants in food, prepared by the seventy-second meeting of JECFA, FAO and WHO, Rome and Italy. WHO Food Additives Series: 63 FAO JECFA Monographs 8, p. 673.

Juhasz, A.L., Smith, E., Weber, J., Rees, M., Rofe, A., Kuchel, T., et al., 2006. In vivo assessment of arsenic bioavailability in rice and its significance for human health risk assessment. Environ. Health Perspect. 114 (12), 1826-1831.
Kientz, K., Jimenez, B.D., Perez, L., Rodriguez-Sierra, C.J., 2003. In vitro bioaccessibility of metals in soils from a superfund site in Puerto Rico. B. Environ. Contam. Tox. 70 (5), 927-934.

Kim, E.J.Y., Chen, Y., Huang, J.Q., Li, K.M., Razmovski-Naumovski, V., Poon, J., et al., 2013. Evidence-based toxicity evaluation and scheduling of Chinese herbal medicines. J. Ethnopharmacol. 146 (1), 40-61.

Ko, R.J., 1998. Adulterants in Asian patent medicines. New Engl. J. Med. 339 (12), 847.

Koch, I., Steven, S., Lai, V.W.M., Owen, A., Reimer, K.J., Cullen, W.R., 2007. Bioaccessibility and excretion of arsenic in Niu Huang Jie Du Pian pills. Toxicol. Appl. Pharmacol. 222 (3), 357-364.

Koch, I., Moriarty, M., House, K., Sui, J., Cullen, W.R., Saper, R.B., et al., 2011. Bioaccessibility of lead and arsenic in traditional Indian medicines. Sci. Total Environ. 409 (21), 4545-4552.

Koh, H.L., Woo, S.O., 2000. Chinese proprietary medicine in Singapore - regulatory control of toxic heavy metals and undeclared drugs. Drug Saf. 23 (5), 351-362.

Liu, J., Shi, J.Z., Yu, L.M., Goyer, R.A., Waalkes, M.P., 2008. Mercury in traditional medicines: is cinnabar toxicologically similar to common mercurials? Exp. Biol. Med. 233 (7), 810-817.

Liu, Y., Wu, J., Wei, W., Xu, R., 2012. Simultaneous determination of heavy metal pollution in commercial traditional Chinese medicines in China. J. Nat. Med. 67 (4), 887-893.

Lu, Y.F., Yan, J.W., Wu, Q., Shi, J.Z., Liu, J., Shi, J.S., 2011. Realgar- and cinnabar-containing An-Gong-Niu-Huang Wan (AGNH) is much less acutely toxic than sodium arsenite and mercuric chloride. Chem. Biol. Interact. 189 (1-2), 134-140.

Marwick, C., 1995. Growing use of medicinal botanicals forces assessment by drug regulators. Jama J. Am. Med. Assoc. 273 (8), 607-609.

Melchart, D., Linde, K., Weidenhammer, W., Hager, S., Liao, J.Z., Bauer, R., et al., 1999. Use of traditional drugs in a hospital of Chinese medicine in Germany. pharmacoepidemiol. Drug Saf. 8 (2), 115-120.

Moreda-Pineiro, J., Moreda-Pineiro, A., Romaris-Hortas, V., Moscoso-Perez, C., Lopez-Mahia, P., Muniategui-Lorenzo, S., et al., 2011. In-vivo and in-vitro testing to assess the bioaccessibility and the bioavailability of arsenic, selenium and mercury species in food samples. Trac-Trend Anal. Chem. 30 (2), 324-345.

Pharmacopeial Committee of China, 2010. Chinese Pharmacopoeia. People's Press, Beijing, China.

Semple, K.T., Doick, K.J., Jones, K.C., Burauel, P., Craven, A., Harms, H., 2004. Defining bioavailability and bioaccessibility of contaminated soil and sediment is complicated. Environ. Sci. Technol. 38 (12), 228A-231A.

Ting, A., Chow, Y., Tan, W., 2013. Microbial and heavy metal contamination in commonly consumed traditional Chinese herbal medicines. J. Tradit. Chin. Med. 33 (1), 119-124. 
U.S. Environmental Protection Agency, 1994. Method 200.8: Determination of Trace Elements in Waters and Wastes by Inductively Coupled Plasma-Mass Spectrometry (Revision 5.4).

United States Pharmacopeial Convention, 2004. United States Pharmacopoeia (Rockville, USA).
Zagury, G.J., Bedeaux, C., Welfringer, B., 2009. Influence of mercury speciation and fractionation on bioaccessibility in soils. Arch. Environ. Contam. Toxicol. 56 (3), 371-379.

Zhang, J., Wider, B., Shang, H., Li, X., Ernst, E., 2012. Quality of herbal medicines: challenges and solutions. Complement. Ther. Med. 20 (1-2), 100-106. 